ORIGINAL ARTICLE

\title{
The laparoscopic nephrectomy learning curve: a single centre's development of a de novo practice
}

\author{
J Phillips, J W F Catto, V Lavin, D Doyle, D J Smith, K J Hastie, N E Oakley
}

Postgrad Med J 2005;81:599-603. doi: 10.1136/pgmj.2004.030148

See end of article for
authors' affiliations
.....................
Correspondence to:
Mr J T Phillips, Department
of Urological Surgery,
Room K130, K Floor,
Royal Hallamshire
Hospital, Glossop Road,
Sheffield S10 2JF, UK;
J.Phillips@sheffield.ac.uk
Submitted
1 November 2004
Accepted
23 February 2005

See end of article for authors' affiliations

Correspondence to: Mr JTPhillips, Department Royal Hallamshire Hospital, Glossop Road Sheffield S10 2JF, UK :

Submitted

Accepted

23 February 2005

\begin{abstract}
Objective: There has been a dramatic increase in the interest and practice of laparoscopic urology, with nephrectomy having become the commonest laparoscopic urological procedure. Compared with open nephrectomy, it results in reduced morbidity and shorter convalescence times while maintaining oncological safety. However, while these results predominately stem from institutions with well developed laparoscopic programmes, little is known about the results in centres that have newly adopted this technique. The introduction of a laparoscopic urological service at the Royal Hallamshire Hospital provided an opportunity to study these factors.

Methods: Since the appointment in October 2000 of a urological surgeon (N Oakley) to develop the laparoscopic service, there have been over 200 laparoscopic procedures including 121 nephrectomies performed at this centre. Full details were collected for each of these cases, and in addition, compared with retrospective data for 50 open nephrectomies performed during the same time period.

Results: With increased operator experience the median operative duration, complication, transfusion, and conversion rates significantly improved. While a learning curve was evident, the overall operative complication (9\%) and conversion rates $(6 \%)$ were low, in addition to patient morbidity (16.5\%) and mortality $(0 \%)$ rates, showing that this learning curve had no deleterious effects upon patient care. The median hospital stay was four days, which reduced to three with experience and was significantly shorter than for open nephrectomy at this institution $(p=0.001)$.

Conclusions: The development of a successful laparoscopic programme can be achieved with a comparatively short learning curve and without detriment to the patient provided the necessary steps are observed.
\end{abstract}

A fter the initial description of laparoscopic nephrectomy, ${ }^{1}$ there has been a dramatic increase in the interest in and practice of laparoscopic urology. Coincident technological and surgical developments ${ }^{2}$ mean that advanced laparoscopic procedures, such as radical prostatectomy, can be performed in many units. The upper urinary tract is particularly suited to the laparoscopic approach and nephrectomy has become the commonest laparoscopic urological procedure. ${ }^{3}$ Reports of this procedure have shown that, when compared with open nephrectomy, it results in reduced morbidity, shorter convalescence times, and potentially reduced costs. ${ }^{4-6}$ Despite initial concerns regarding tumour dissemination, recent work has established the oncological safety of the laparoscopic approach ${ }^{7}$ and it is now an established method for performing radical and partial nephrectomy for renal cell carcinoma (RCC) ${ }^{9}$ and nephroureterectomy for upper tract transitional cell carcinoma (TCC). ${ }^{10}$

However, there is a significant learning curve with laparoscopy ${ }^{11}$ and the widespread introduction of this technique requires careful monitoring and supervision. While the excellent results of laparoscopic surgery from experienced institutions are well established, ${ }^{12}$ little is known about the development of laparoscopy and its results outside these institutions. The introduction of a laparoscopic urological service at our institution provided an opportunity to study these factors in a large British teaching hospital.

\section{METHODS}

The Royal Hallamshire Hospital (RHH) is a tertiary referral centre in the North Trent region of the UK, covering 500000 patients. Since the appointment, in October 2000, of a urological surgeon (NEO) to develop the laparoscopic service, there have been over 200 laparoscopic procedures (including
121 nephrectomies). Full details were collected for each patient including their source of referral, indications for nephrectomy, and details of their postoperative rehabilitation. Intraoperative details, such as duration, surgical complications, and blood loss, were collected prospectively at the time of surgery. Operative duration was measured from the time an anaesthetised patient entered theatre (including positioning and draping) to extubation. Incomplete data were present in 20 patients.

\section{Surgical procedure for nephrectomy}

The retroperitoneal approach to the kidney is our preferred route to perform the nephrectomy. For this the patient is positioned laterally with a minor degree of table break to remove any obvious skin crease. Our standard approach uses three ports, with an open Hassan's cut down to obtain the initial access and balloon dissection of the retroperitoneal space (Tyco Healthcare). ${ }^{13}$ Subsequent ports are inserted under direct vision, and additional $5 \mathrm{~mm}$ ports are inserted, when required, for secondary retraction by an assistant.

The nephrectomy is performed outside Gerota's fascia and the peri-renal fat, using a similar plane as for the open radical procedure. The renal artery is clipped five times (using titanium clips) and divided between clip number 3 and 4, leaving three clips on the patient's renal artery stump. The vein is also clipped five times, with non-absorbable locking clips (Hemolock Weck closure system), and divided between number 3 and 4 . The specimen is placed into an impermeable sack before removal via an iliac fossa port. For benign pathology, the specimen is morcellated with scissors and

Abbreviations: RCC, renal cell carcinoma; TCC, transitional cell carcinoma 


\begin{tabular}{|lll|}
\hline Table 1 & Indications for nephrectomy & \\
\hline Indication & & Number \\
\hline Malignant & Renal cell carcinoma & 31 \\
& Transitional cell carcinoma & 21 \\
Benign & Staghorn calculus & 24 \\
& PUJ obstruction & 22 \\
& Chronic infection & 17 \\
& Other (tuberculosis, polycystic & 6 \\
& disease, medullary sponge kidney, \\
& oncocytoma, malignant & \\
& hypertension) & 121 \\
\hline & Total \\
\hline
\end{tabular}

grasping forceps, before removal of the fragments piecemeal. The specimen is removed intact for malignant disease, permitting formal pathological staging. Nephroureterectomy is performed by combining laparoscopic mobilisation of the kidney with either endoscopic resection and closure of the VUJ (for upper ureter and renal pelvic TCC) or an open approach to the VUJ (for lower ureteric tumours).

\section{RESULTS}

The patients undergoing nephrectomy had a median age of 60 years, a median weight of $71 \mathrm{~kg}$, and the majority were female $(61 \%)$. Previous abdominal surgery had been performed in 38 patients, 15 cases of which involved the retroperitoneum. Patients were referred from three sources; general practitioners for a urological opinion (29\%) or RHH consultants (47\%) and non-RHH consultants (24\%) for a laparoscopic opinion. Complete nephrectomy was performed in 115 cases, of which 61 were simple, 29 were radical, and 25 were nephroureterectomies. Partial nephrectomy (for renal carcinoma (4) and localised symptomatic stones disease (2)) was performed in six patients. Table 1 shows the indications for nephrectomy.

The nephrectomy frequency increased steadily throughout this three year period (fig 1), reflecting both unit development and an increase in patient referral as the service is established. For example, the first case from another hospital was the 13th patient, while 7 of 26 of the most recent cases were from other hospitals. Retroperitoneoscopic nephrectomy, our preferred route, was performed in $87 \%$ of cases, with perinephric inflammation $(n=13)$ or large tumour size $(\mathrm{n}=3)$ in the remaining cases making the transperitoneal route preferable. Nephrectomy was performed using three ports in $89 \%$ of patients, with 13 patients requiring additional ports (four ports in 10 cases and five in three cases).

While the overall median operative duration was $150 \mathrm{~min}$ utes (IQ range 130-180), the median duration and variance of the operative time reduced with increased surgical experience (fig 2). The median (SD) duration of the first quarter of cases (169 (67) minutes) was significantly longer than that of the final 30 cases $\left(\begin{array}{ll}138 & (42) \text { minutes, } t \text { test } p=0.05\end{array}\right)$. Furthermore, if nephroureterectomies are excluded, the median operative time was less, and for the last 30 cases was 120 minutes.

All operations were completed successfully, with seven cases $(6 \%)$ requiring conversion to open nephrectomy (table 2). The reasons for conversion were failure to progress secondary to adhesions (in three cases), uncontrollable haemorrhage (two cases), IVC trauma (one case), and intraperitoneal port placement resulting in inability to maintain the pneumoretroperitoneum (one case). With the exception of the cross stapled IVC (repaired through a rooftop incision), each conversion was accomplished through an incision created by joining two of the laparoscopic port sites. The conversion rate decreased with experience (six

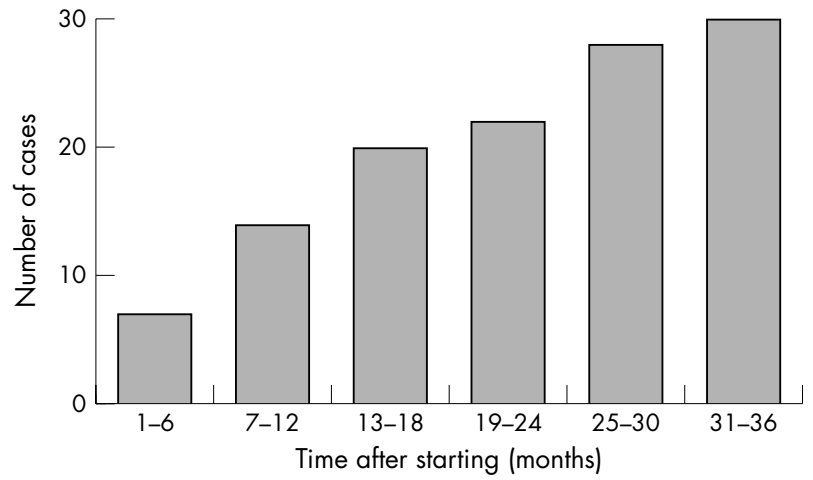

Figure 1 Increasing workload with unit development. The number of nephrectomies performed in each six month interval steadily increased over the three year period.
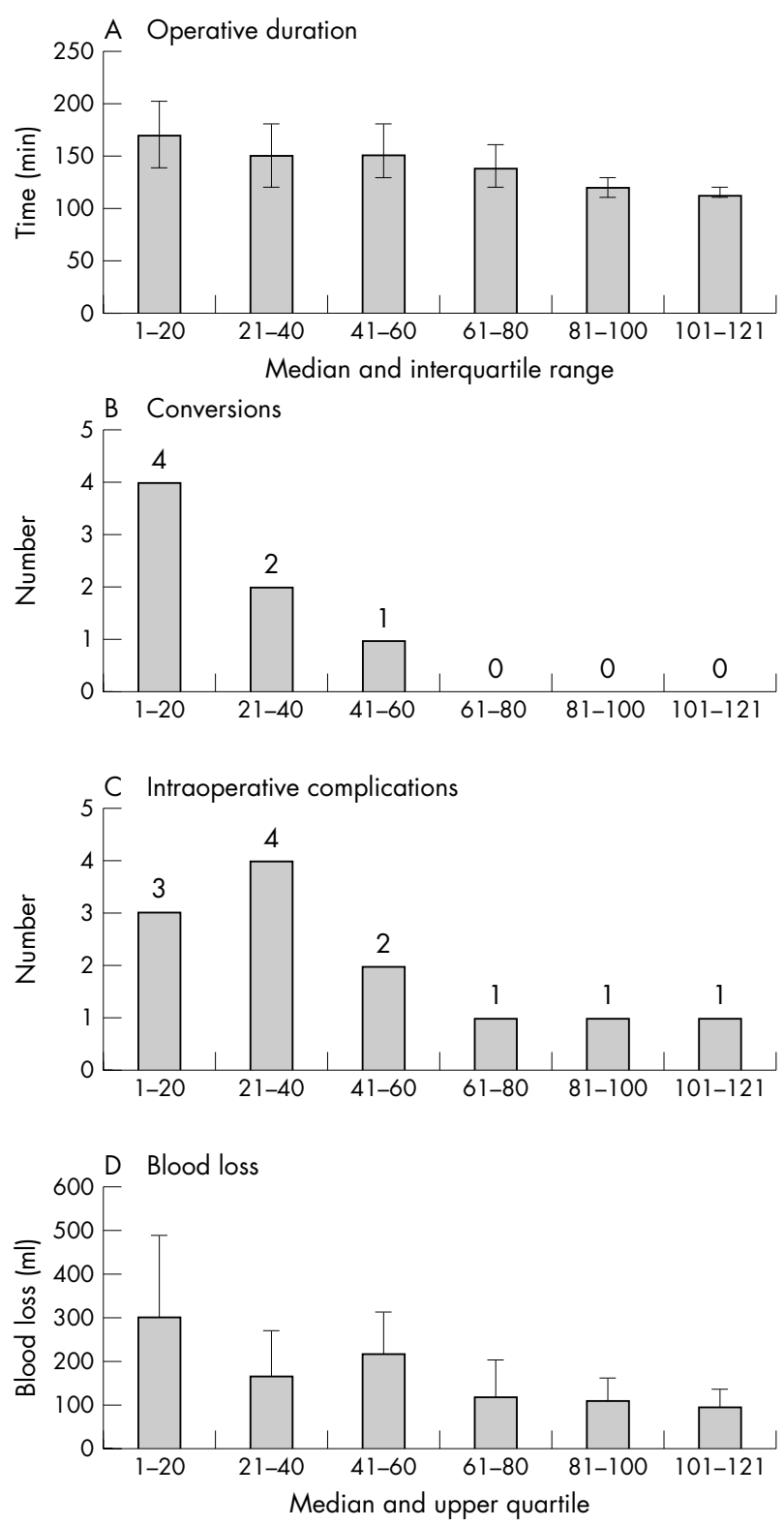

Figure 2 Intraoperative details for the 121 consecutive laparoscopic nephrectomy cases. 


\begin{tabular}{ll|}
\hline $\begin{array}{l}\text { Table } 2 \text { Reasons for conversion to open } \\
\text { nephrectomy (seven patients (6\%) required } \\
\text { conversion) }\end{array}$ \\
\hline Reason for conversion & Number \\
\hline Adhesions & 3 \\
Uncontrollable haemorrhage & 2 \\
IVC trauma & 1 \\
Intraperitoneal port placement & 1 \\
\hline
\end{tabular}

conversions in the first 18 months compared with one conversion in the last 18 months, $\left.\chi^{2} \mathrm{p}=0.01\right)$. The mean blood loss was $137 \mathrm{ml}$ (range $0-2000 \mathrm{ml}$ ) and 14 patients $(11.5 \%)$ required blood transfusion (mean $=3$ units (range 2-8)).

While there were no patient deaths in this series, 12 patients $(10 \%)$ had significant intraoperative complications, and these are listed in table 3.

Postoperatively two patients underwent open exploration of the renal bed (in the few hours after surgery) for refractory hypotension suggestive of haemorrhage, but in neither case a significant bleeding vessel was identified. Twenty patients (16.5\%) suffered other postoperative complications and these are listed in table 4.

According to a developed anaesthetic protocol most patients $(64 \%)$ had an epidural for analgesia, which stayed for a median of one day. A mean of $10 \mathrm{mg}$ morphine and $12 \mathrm{~g}$ paracetamol was additionally required for analgesia. The median time for the return of functions after surgery was one day for drinking (range 0-4 days), two days for eating (range 1-7), two days for mobilisation (1-6), and four days for discharge (2-18). These compared favourably with the same parameters for the last 50 open nephrectomies performed during the same period (fig 3).

\section{DISCUSSION}

Our results represent the initiation and development of a large retroperitoneoscopic nephrectomy series. They show that there is a learning curve associated with laparoscopy, but it is of minimal consequence to the patient if undertaken by a responsible team and with the support of non-laparoscopic colleagues. They show that the benefits of the laparoscopic approach to the urinary tract are applicable to units outside those institutions with longstanding laparoscopic practices and that the retroperitoneal route to the kidney and its adnexae can be learnt without significant morbidity and mortality.

The learning curve of laparoscopic surgery is poorly defined, a concern to many potential laparoscopic surgeons ${ }^{14}$ and may be different for individual surgeons, procedures, and routes taken. For example, retroperitoneoscopic renal surgery lacks visible anatomical landmarks, has lots of perinephric fat, and a limited working space when compared with transperitoneal surgery. To investigate the effect of operator

Table 3 Intraoperative complications (12 patients $(10 \%)$ encountered complications during surgery)

\begin{tabular}{ll}
\hline Complication & Number \\
\hline Bleeding & 4 \\
Peritoneal tear & 5 \\
Urine extravasation & 1 \\
IVC cross stapling & 1 \\
Rupture of the specimen sac & 1 \\
\hline
\end{tabular}

Table 4 Postoperative complications (in total, 20 patients (16.5\%) suffered from 24 complications after surgery)

\begin{tabular}{lll}
\hline Complication & & Number \\
\hline Respiratory & Atelectasis & 3 \\
\multirow{2}{*}{ Cardiovascular } & Pneumonia & 1 \\
\multirow{2}{*}{ Wound } & Hecardial infarction & 1 \\
& Haemailure & 2 \\
& Persistent leak & 5 \\
\multirow{2}{*}{ Gastrointestinal } & 1 \\
& Subcostal neuropraxia & 1 \\
General & Psoas haematoma & 1 \\
& Haematemesis & 3 \\
& Confusion & 1 \\
& Jaundice & 1 \\
\hline
\end{tabular}

experience Higshihara et al studied eight surgeons with between 12-48 months laparoscopic experience. ${ }^{11}$ The authors found that while the open conversion rate, transfusion rate, and blood loss did not differ with increasing experience, operations became significantly quicker. We also found that the operative duration was a good marker of the learning curve, with it (and blood loss) reaching their median values (similar to multi-institutional published results) ${ }^{12}$ after 20 cases. While the intraoperative complication rate peaked after 20 cases (between 21-40 cases (fig 2)) this may not reflect a learning curve as there are few complications in each time period (four compared with two). Significantly, a change of practice also occurred during this phase of development as more difficult cases were performed including radical nephrectomy and complex simple nephrectomy (cases with previous surgery).

The learning curve in our series represents the improvement of both surgeon, from experience and practice, and the entire team at managing laparoscopic patients. While surgical improvement can be detected by the reduced operative duration, blood loss, and complications, it is harder to measure the improvement in other care aspects. In terms of hospital stay, our median time of four days compared less favourably than the length of stay from some of the other published series. However, our increased experience facilitated the introduction of an integrated care pathway to streamline patient rehabilitation, after which there was a trend for quicker discharge, and for our last 30 cases the median hospital stay was three days. This compared favourably against the median stay of 6.5 days from open nephrectomy at our institution ( $t$ test $\mathrm{p}<0.001$ ), confirming the financial and rehabilitatory advantages of the laparoscopic approach.

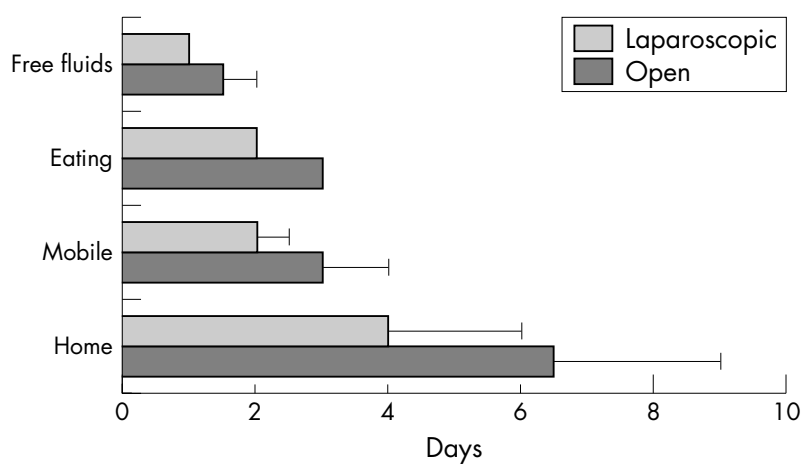

Figure 3 Open compared with laparoscopic recovery times (median plus upper quartile shown). 
Table 5 Comparison with the literature from the past 10 years (2063 patients from 23 published series)

\begin{tabular}{|c|c|c|c|c|}
\hline & $\begin{array}{l}\text { RHH } \\
\text { (all } 121 \text { cases) }\end{array}$ & Literature & $\begin{array}{l}\text { RHH } \\
\text { (last } 30 \text { cases) }\end{array}$ & $\begin{array}{l}\text { p Value (last } 30 \\
\text { against first } 91 \\
\text { cases) }\end{array}$ \\
\hline $\begin{array}{l}\text { Duration } \\
\text { Blood loss } \\
\text { Complication rate } \\
\text { Conversion rate } \\
\text { Oral intake } \\
\text { Home }\end{array}$ & $\begin{array}{l}140 \mathrm{~min} \\
130 \mathrm{ml} \\
17 \% \\
6 \% \\
1 \text { day } \\
4 \text { days }\end{array}$ & $\begin{array}{l}160 \mathrm{~min} \\
190 \mathrm{ml} \\
15.4 \% \\
5 \% \\
1 \text { day } \\
4.1 \text { days }\end{array}$ & $\begin{array}{l}120 \mathrm{~min} \\
105 \mathrm{ml} \\
12 \% \\
0 \% \\
1 \text { day } \\
3 \text { days }\end{array}$ & $\begin{array}{l}0.012^{*} \\
0.871 \\
0.847 \\
0.201 \\
0.902 \\
0.192\end{array}$ \\
\hline
\end{tabular}

To disseminate laparoscopic urology in the UK a programme of training and education has been implemented by the British Association of Urological Surgeons (BAUS) and a mentor scheme is being developed. ${ }^{15}$ Thus competent laparoscopic surgeons train colleagues in dry and wet laboratories before teaching progresses to mentored cases. To develop the trainee's competency, they may perform a number of cases assisted by the trainer at their own institution. Fabrizio et al reported the use of such a scheme for laparoscopic radical prostatectomy and found that it decreased the learning curve of individual surgeons, while maintaining operative standards. ${ }^{16}$ Similar results were found by Frahat et al, using a mentored approach to train for paediatric laparoscopic renal surgery, who also reiterated the importance of continued assessment of laparoscopic results. ${ }^{17}$ Thus, the mentored approach to laparoscopic training, when combined with objective assessment, ${ }^{18}$ seems to be the best model for the widespread implementation of laparoscopic urology.

While our series seems to show a learning curve, improved results with increased experience, it does not detrimentally affect patient care. Seventy five per cent of our intraoperative complications and $100 \%$ of conversions to open nephrectomy occurred in the first 60 patients, and the overall intraoperative and postoperative complication rates seem similar to those from previously published reports (see table 5). ${ }^{5}$ Fahlenkamp et al reviewed 2407 laparoscopic procedures from four German institutions and found the operative complication rate for nephrectomy $(\mathrm{n}=351)$ was $8.2 \% .{ }^{19}$ The authors divided laparoscopic injuries into those related to access (for example, trocar related), dissection, laparoscopic technique associated (for example, hypercarbia, emphysema), and complications of the wound. Their results showed that most complications were related to surgical dissection and resulted in bleeding or visceral damage. Of note, there were fewer visceral injuries by surgeons using the retroperitoneal rather than transperitoneal approach to the kidney and the complication rate reduced with increasing experience, from $13.3 \%$ (for the first 100 cases) to 3.6\%. Soulie et al reviewed 171 retroperitoneal nephrectomies from three French institutions and found a complication rate of $15.8 \%,{ }^{20}$ while Vallancien et al found in their series of 1311 laparoscopic procedures, of which 162 were renal procedures, a complication rate of $12 \%$ and a conversion rate of $7 \% .{ }^{21}$ Gill et al reviewed the first 185 nephrectomies performed at five centres in the USA and found a complication rate of $16 \%$, which led to a prolonged hospital stay in most cases $(77 \%))^{22}$ More recent reports from the Cleveland clinic have focused on individual laparoscopic renal procedures and have shown major complications in $4 \%$ of radical nephrectomies ${ }^{23}$ and $12 \%$ of nephroureterectomies. ${ }^{24}$

In conclusion, our results represent the de novo development of a contemporary laparoscopic practice at a single UK centre, and show that the development of a successful laparoscopic programme can be achieved in units outside those institutions with longstanding laparoscopic practices. The benefits of this approach to the kidney are numerous and should not be denied to patients because of lack of availability. The retroperitoneal route to the kidney and its adnexae can be learnt without significant morbidity and mortality, and the significant advantages in terms of reduced postoperative pain, shorter hospital stay, rapid convalescence, and better cosmesis make this the gold standard technique for nephrectomy, and offer strong incentives for urologists and patients alike. We believe that the laparoscopic approach to the kidney is now the default approach to the kidney for benign and malignant disease, although their remains an ever reducing number of absolute and relative indications for open nephrectomy. The acquisition of the necessary skills and experience to perform laparoscopic nephrectomy, for benign pathology and small to moderately sized renal tumours (including TCC of the upper urinary tract), can be obtained with a comparatively short learning curve and without detriment to the patient provided the necessary steps are observed. Novel techniques to deal with these pathologies should now be judged against the results from laparoscopic surgery..$^{25}$

\section{ACKNOWLEDGEMENTS}

The authors thank the urological consultants in the North Trent region and especially those at the Royal Hallamshire Hospital; Messrs Anderson, Chapple, Cutinha, Hall, Hamdy, Rosario, and Tophill for their support during the development of this laparoscopic practice.

\section{Authors' affiliations}

J Phillips, J W F Catto, V Lavin, D J Smith, K J Hastie, N E Oakley, Department of Urological Surgery, Royal Hallamshire Hospital, Sheffield, UK

D Doyle, Department of Anaesthetics, Royal Hallamshire Hospital

Funding: NEO received a British Association of Urological Surgeons Section of Endourology travelling fellowship to Washington University, St Lovis and the Cleveland clinic in 2000, and a British Urological Foundation fellowship to the Cleveland clinic in 2003.

Conflicts of interest: none.

\section{REFERENCES}

1 Clayman RV, Kavoussi LR, Soper NJ, et al. Laparoscopic nephrectomy: initial case report. J Urol 1991; 146:278-82.

2 Guillonneau B, Vallancien G. Laparoscopic radical prostatectomy: the Montsouris technique. J Urol 2000;163:1643-9.

3 Siqueira TM, Kuo RL, Gardner TA, et al. Major complications in 213 laparoscopic nephrectomy cases: the Indianapolis experience. J Urol 2002;168:1361-5.

4 Fornara P, Doehn C, Friedrich HJ, et al. Non-randomized comparison of open flank versus laparoscopic nephrectomy in 249 patients with benign renal disease. Eur Urol 2001;40:24-31.

5 Gill IS, Clayman RV, McDougall EM. Advances in urological laparoscopy J Urol 1995; 154:1275-94.

6 Meraney AM, Gill IS. Financial analysis of open versus laparoscopic radical nephrectomy and nephroureterectomy. J Urol 2002;167:1757-62.

7 Cicco A, Salomon L, Hoznek H, et al. Carcinological risks and retroperitoneal laparoscopy. Eur Urol 2000;38:606-12. 
8 Rassweiler J, Tsivian A, Kumar A, et al. Oncological safety of laparoscopic surgery for urological malignancy: experience with more than 1,000 operations. J Urol 2003;169:2072-5.

9 Lam JS, Shvarts O, Pantuck AJ. Changing concepts in the surgical management of renal cell carcinoma. Eur Urol 2004:45:692-705.

10 El Fettouh HA, Rassweiler JJ, Schulze M, et al. Laparoscopic radical nephroureterectomy: results of an international multicenter study. Eur Urol 2002;42:447-52.

11 Higashihara E, Baba S, Nakagawa K, et al. Learning curve and conversion to open surgery in cases of laparoscopic adrenalectomy and nephrectomy. J Urol 1998;159:650-3.

12 Bishoff JT, Kavoussi LR. Laparoscopic surgery of the kidney. In: Campbell MF, Walsh PC, Retik AB, eds. Campbell's urology. Philadelphia: Saunders, 2002:2732-84.

13 Rassweiler JJ, Henkel TO, Stoch C, et al. Retroperitoneal laparoscopic nephrectomy and other procedures in the upper retroperitoneum using a balloon dissection technique. Eur Urol 1994;25:229-36.

14 Vogeli TA, Burchardt $M$, Fornara $P$, et al. Current laparoscopic practice patterns in urology: results of a survey among urologists in Germany and Switzerland. Eur Urol 2002;42:441-6.

15 McNeill SA, Tolley DA. Laparoscopy in urology. BJU Int 2002;89: 169-73.

16 Fabrizio MD, Tuerk I, Schellhammer PF. Laparoscopic radical prostatectomy: decreasing the learning curve using a mentor initiated approach. J Urol 2003;169:2063-5.
17 Farhat W, Khoury A, Bagli D, et al. Mentored retroperitoneal laparoscopic renal surgery in children: a safe approach to learning. BJU Int 2003;92:617-20.

18 Gettman MT, Kondraske GV, Traxer O, et al. Assessment of basic human performance resources predicts operative performance of laparoscopic surgery. J Am Coll Surg 2003;197:489-96.

19 Fahlenkamp D, Rassweiler J, Fornara P, et al. Complications of laparoscopic procedures in urology; experience with 2407 procedures at 4 German centres. J Urol 1999:162:765-70.

20 Soulie M, Salomon L, Seguin P, et al. Multi-institutional study of complications in 1085 laparoscopic urological procedures. Urology $2001 ; 58: 899-903$.

21 Vallancien G, Cathelineau X, Baumert H, et al. Complications of transperitoneal laparoscopic surgery in urology: review of 1,311 procedures at a single center. J Urol 2002;168:23-6.

22 Gill IS, Kavoussi LR, Clayman RV, et al. Complications of laparoscopic nephrectomy in 185 patients: a multi-institutional review. J Urol 1995; 154:479-83.

23 Gill IS, Meraney AM, Schweizer DK, et al. Laparoscopic radical nephrectomy in 100 patients: a single centre experience from the United States. Cancer 2001;92:1843-55.

24 Gill IS, Sung GT, Hobart MG, et al. Laparoscopic radical nephroureterectomy for upper tract transitional cell carcinoma: the Cleveland Clinic experience. J Urol 2000;164:1513-22.

25 Breda G, Nakada SY, Rassweiler JJ. Future developments and perspectives in laparoscopy. Eur Urol 2001;40:84-91.

\section{bmjupdates+}

bmiupdates+ is a unique and free alerting service, designed to keep you up to date with the medical literature that is truly important to your practice.

bmjupdates+ will alert you to important new research and will provide you with the best new evidence concerning important advances in health care, tailored to your medical interests and time demands.

Where does the information come from?

bmjupdates+ applies an expert critical appraisal filter to over 100 top medical journals A panel of over 2000 physicians find the few 'must read' studies for each area of clinical interest

Sign up to receive your tailored email alerts, searching access and more...

www.bmjupdates.com 